\title{
The aqueous extract of brucea javanica reduces tumorigenicity of human lung cancer tumorspheres
}

\author{
Seung-Hun Kim¹, Po-Wei Fan', Chang-Heng Hsieh', Hsuan-Yuan Lin ${ }^{1}$, Wen-Hsin Wang', Ming-Chung Lee², \\ Kang Fang ${ }^{1}$
}

${ }^{1}$ School of Life Science, Department of Life Science, National Taiwan Normal University, Taipei 116, Taiwan.

${ }^{2}$ Brion Research Institute of Taiwan, New Taipei City 231, Taiwan.

Correspondence to: Prof. Kang Fang, School of Life Science, Department of Life Science, National Taiwan Normal University, 88, Sec 4, Ting-Chou Road, Taipei 116, Taiwan. E-mail: kangfang8150@gmail.com

How to cite this article: Kim SH, Fan PW, Hsieh CH, Lin HY, Wang WH, Lee MC, Fang K. The aqueous extract of brucea javanica reduces tumorigenicity of human lung cancer tumorspheres. Cancer Drug Resist 2021;4:866-80.

https://dx.doi.org/10.20517/cdr.2021.58

Received: 25 Jun 2021 First Decision: 3 Aug 2021 Revised: 4 Aug 2021 Accepted: 12 Aug 2021 First online: 13 Aug 2021

Academic Editor: Godefridus J. Peters Copy Editor: Yue-Yue Zhang Production Editor: Yue-Yue Zhang

\begin{abstract}
Aim: Therapy to overcome drug resistance by modulating epidermal growth factor receptor (EGFR) is a viable approach to suppress the proliferation of human non-small cell lung cancer (NSCLC) cells. A previous study demonstrated that the seeds of an aqueous Brucea javanica (BJ) (L.) Merr (Simaroubaceae) extract containing quassinoid mixtures effectively inhibited the growth and alleviated tumorigenesis in H1975 cells of NSCLC by targeting T790M/L858R EGFR. This study aimed to further determine whether the aqueous BJ extract affects the enriched H1975 spheroids in suspension culture and mouse xenograft tumor models.
\end{abstract}

Methods: The spheroids of NSCLC adenocarcinoma H1975 cells were enriched in a serum-free media. The growth rate of sphere propagation by aqueous BJ extract was determined in suspended culture and in colony-formation assay. BJ extract was fed orally to nude mice bearing xenograft tumors. The resected tumors were analyzed by hematoxylin and eosin staining, terminal deoxynucleotidyl transferase-mediated dUTP nick-end labeling assay, and proliferating cell nuclear antigen assessment. Various markers were used to determine the pluripotency of tumors from mice treated with different concentrations of BJ extract.

Results: BJ extract was demonstrated to be effective against the propagation of the enriched spheroids. In animal models, oral administration of the aqueous BJ extract reduced spheroid tumorigenicity. The alleviated growth of the established xenograft tumors can be attributed to the reduced drug resistance and induced apoptosis without 
distinct adverse effects. More evidence supports activated apoptotic death attenuated spheroid stemness of tumors.

Conclusion: As an effective treatment regime to assuage lung cancer, the indigenous BJ extract promises to obliterate drug resistance and the growth of cancer stem cell tumors from NSCLC cells harboring T790M/L858R EGFR.

Keywords: Brucea javanica, cancer stem cells, drug resistance, epidermal growth factor receptor, lung cancer, apoptosis

\section{INTRODUCTION}

Finding strategies against drug-resistant cancer stem-like cells (CSCs) to reinforce the conventional cancer treatment is a challenging task ${ }^{[1]}$. The minor cell subpopulations within the CSCs are closely related to the onset of malicious non-small cell lung cancer (NSCLC) tumors. The minor and slow-dividing CSCs refractive to various treatments account for the recurrence of lung tumors ${ }^{[2]}$. The enriched progenitor clusters propagate in the environment of serum-free medium with supplementation of growth factors. The enriched spheroid fractions commonly referred to as CSCs can be suspended and propagated as tumorspheres ${ }^{[2,3]}$.

Epidermal growth factor receptor (EGFR) signal activation in NSCLC cells contributes to tumor growth and impedance to apoptosis. Measures to subdue resistance to EGFR inhibitors turned out to be an immense obstacle in treating NSCLC patients ${ }^{[4]}$. The biomarker exhibiting mutated EGFR at L858R in NSCLC patient is a prerequisite for the effectiveness of tyrosine kinase inhibitors (TKIs) such as gefitinib ${ }^{[5]}$. However, the progressive EGFR mutation at amino acid 790 (T790M) during TKI therapy increasingly blocked steric binding of the drug followed by severe therapy resistance ${ }^{[6,7]}$. This complication prompted more development in therapy by targeting the durable stem-like cell populations that are resistant to TKI because of the evolved double mutant $\mathrm{EGFR}^{[8,9]}$. More evidence supports that, by targeting populations of CSC comprising aberrant EGFR, the growth of NSCLC can be suppressed and, finally, eradicated ${ }^{[3]}$. Thus, to develop new efficient therapeutic drugs, improvements for suppressing NSCLC cells of mutated EGFR are crucial in attenuating growth of malignant tumors ${ }^{[7,10]}$.

Indigenous plants are frequently known to revert multi-drug resistance by activating cell death during cancer treatment ${ }^{[11]}$. One of the commonly accepted herb medicines is from the fruits of Brucea javanica (BJ) (L.) Merr, a plant species of the evergreen shrub family Simaroubaceae widely distributed in Southeast Asia and northern Australia ${ }^{[12]}$. For years, the harvested fruits have been widely accepted as a remedy for diseases in East Asia and a traditional medicine ${ }^{[13]}$. The BJ fruits were proved potent against pancreatic cancer growth $^{[14]}$. The ethyl acetate extract of the seeds can cure patients with inflammatory diseases ${ }^{[15]}$ and allergy $^{[0]}$. The fruits were also efficacious in suppressing the growth of various types of cancer ${ }^{[14,16,17]}$. A combination of chemotherapy drugs with javanica oil emulsion is used to treat gastric cancer ${ }^{[18]}$ and lung adenocarcinoma $^{[19]}$. Other reports indicate that aqueous BJ extract inhibited the growth of liver cancer cells and the enriched spheroids ${ }^{[20]}$.

The malignant tumorspheres are a minor population of cells endowed with CSC characteristics. The malicious tumor-initiating cells tend to recur and invade, and they are metastatic and resistant to therapy as neoplasm progresses ${ }^{[21]}$. The inherent self-renewal abilities in tumorspheres lead to resistance to environmental affronts and drug intervention ${ }^{[8]}$. BJ extract was demonstrated effective against tumor development of NSCLC cells with EGFR carrying T790M/L858R ${ }^{[22]}$. To demonstrate more translational 
values, it is imperative to learn if the aqueous BJ extract prevents the propagation of three-dimensional spheres of lung cancer cells. To serve this purpose, cells were enriched to form spheroids, in which the development of intrinsic stemness and epithelial-mesenchymal transition (EMT) features of CSCs were assessed. The study began with determining the sensitivity of the aqueous extract against H1975 cell spheroids followed by animal model evaluation. The aim was to determine whether BJ is effective against minor but malicious lung cancer tumorspheres.

\section{METHODS}

\section{Liquid chromatography and mass spectrometry (LC/MS) fingerprint analysis}

The LC/MS method was used to identify the major bioactive substances, which included a Shimadzu LC20AD UFLC system linked to an LC/MS-8040 triple quadrupole mass spectrometer. The running condition included gradient elution with a mixture of mobile phases A $(0.1 \%$ formic acid and $1 \mathrm{~g} / \mathrm{L}$ solution of ammonium acetate in water) and B ( $0.1 \%$ formic acid and $1 \mathrm{~g} / \mathrm{L}$ solution of ammonium acetate in methanol) at Minutes 0-40 with the ratio of $100 \%$ to $70 \% \mathrm{~A}$ and $0 \%$ to $30 \% \mathrm{~B}$; at Minutes $40-70$ with the ratio of $70 \%$ to $0 \% \mathrm{~A}$ and $30 \%$ to $100 \% \mathrm{~B}$; at Minutes $70-70.1$ with the ratio of $0 \%$ to $100 \% \mathrm{~A}$ and $100 \%$ to $0 \%$ $\mathrm{B}$; and at Minutes $70.1-80$ with the ratio of $100 \% \mathrm{~A}$ and $0 \% \mathrm{~B}$. The flow rate was set at $0.4 \mathrm{~mL} / \mathrm{min}$ and the column temperature kept at $40{ }^{\circ} \mathrm{C}$. The injection volume was adjusted to $30 \mu \mathrm{L}$, and the analytical column used a Shimadzu Shim-pack XR-ODS II column $(2.2 \mu \mathrm{m}, 2 \mathrm{~mm} \times 100 \mathrm{~mm}$, Shimadzu). Dual ion modes [electrospray ionization ESI (+) and ESI (-)] were used in MS detection and the transmission of $[\mathrm{M}+\mathrm{H}]^{+}$and $[\mathrm{M}-\mathrm{H}]^{-}$was set as the optimum condition. The MS detection was arranged as a full scan range (400-800 amu). The interface voltages were set at $4.5 \mathrm{kV}$ for ESI (+) and $-3.5 \mathrm{kV}$ for ESI (-). With nitrogen as the nebulizing and drying gas, the flow was set at 3.0 and $10 \mathrm{~L} / \mathrm{min}$, respectively. Argon as the collision-induced dissociation gas was kept at $230 \mathrm{kPa}$. Desolvation line temperature was set at $150{ }^{\circ} \mathrm{C}$, and the heat block temperature was maintained at $400{ }^{\circ} \mathrm{C}$.

\section{Cell culture}

Human NSCLC cells H1975 [CD133 rich, two mutations in EGFR (T790M /L858R)] were acquired from American Type Culture Collection (Manassas, VA) and cultured in $75 \mathrm{~cm}^{2}$ tissue culture flasks. The cells were cultured in Dulbecco's Modified Eagle Medium (DMEM) containing 10\% fetal bovine serum (FBS) (Thermo Fisher Scientific, Waltham, MA, USA), $100 \mathrm{unit} / \mathrm{mL}$ penicillin, and $100 \mu \mathrm{g} / \mathrm{mL}$ streptomycin and maintained at $37^{\circ} \mathrm{C}$ in the environment of humidified incubator with $5 \% \mathrm{CO}_{2}$.

\section{Chemicals and reagents}

Sun Ten Pharmaceutical (Taichung, Taiwan) provided the aqueous extract of the whole BJ plant for experiments. Briefly, $100 \mathrm{~g}$ of the collected materials were extracted with sterile water as previously published ${ }^{[20]}$. The samples of the final concentrates were adjusted to make a concentration of $1 \mathrm{~g} / \mathrm{mL}$ and stored at $25{ }^{\circ} \mathrm{C}$. The chemicals 4',6-diamidino-2-phenylindole (DAPI), crystal violet, penicillinstreptomycin, glutamine, trypsin-EDTA, and DMEM medium were obtained from Thermo Fisher Scientific (Waltham, MA, USA).

\section{Enrichment of spheroids}

To enrich undifferentiated tumorspheres, NSCLC adenocarcinoma H1975 cells were cultured with serumfree DMEM-F12 medium (Thermo Fisher Scientific) in ultra-low attachment tissue culture plates to maintain cell suspension (Corning, Corning, NY). The culture condition included N-2 Plus Media Supplement (R\&D Systems, Minneapolis, MN), B-27 Supplement (Thermo Fisher Scientific), 20 ng/mL of epidermal growth factor (Pepro Tech, Rocky Hill, NJ), and $10 \mathrm{ng} / \mathrm{mL}$ of basic fibroblast growth factor (bFGF) (Pepro Tech). The floating sphere cultures were expanded by mechanical dissociation, followed by re-plating single cells in a fresh medium. For maintenance, one-third of the serum-free media was replaced 
every 3 days. The collected spheroids were subjected to subsequent experiments in non-adherent culture conditions. Spheroid diameters were measured using Image-Pro Plus 6.3 (Media Cybernetics, Bethesda, $\mathrm{MD})$.

\section{Colony-formation assay}

The growth of spheroids was determined by a colony formation assay. A total of $1 \times 10^{6}$ cells per well in 75 $\mathrm{cm}^{2}$ ultra-low attachment tissue culture plates were raised in growth factor-supplemented medium for 7 days to allow the spheroids to reach a size of more than $50 \mu \mathrm{m}$ in diameter. The spheres were then treated with different concentrations of BJ extract for $12 \mathrm{~h}$, and the mixtures were cultured in soft agar with $0.5 \%$ agarose on top and $0.3 \%$ agar on bottom layers. After 28 days, the plates were stained with $0.002 \%(\mathrm{w} / \mathrm{v})$ crystal violet and incubated at $37^{\circ} \mathrm{C}$ for $30 \mathrm{~min}$. Following removal of the dye solution, colonies of more than 50 cells were counted as positive. Three individual experiments were conducted for each condition.

\section{Western blot analysis of spheroid cell lysates}

The spheroids were formed by plating $1 \times 10^{6}$ cells per well in serum-free media with supplementation of growth factors and treated with various concentrations of aqueous extractions of BJ $(0,5,10$, and 15 $\mathrm{mg} / \mathrm{mL}$ ) for $12 \mathrm{~h}$. The harvested cell pellets were lysed and the protein concentrations determined using a Bio-Rad protein assay kit for (Hercules, CA, USA) before being resolved by electrophoresis and transferred to nitrocellulose membrane. The blots were blocked with 5\% non-fat milk and incubated with 1:2000 dilutions of primary antibodies, including anti-pAkt (GTX128414); anti-PARP (GTX112864); anti-EGFR (GTX121919); anti-pEGFR (GTX61507), anti-ABCG2 (GTX100437), anti-Nanog (GTX100863), anti-CD133 (GTX100567), anti-Sox2 (GTX627405), and anti-ALDH1A1 (GTX123973), from GeneTex. Membranes were then incubated with $0.3 \mu \mathrm{g} / \mathrm{mL}$ of peroxidase-conjugate anti-mouse or anti-rabbit IgG (Thermo Fisher Scientific) and detected with enhanced chemiluminescence substrate (Thermo Fisher Scientific). The loading control was incubated with anti-GAPDH antibody (GTX100118, GeneTex). The signals were visualized with enhanced LAS-4000 (FUJIFILM) apparatus and the band intensities of images analyzed using ImageJ software.

\section{Bromodeoxyuridine incorporation of spheroids}

The assays followed the published procedures ${ }^{[20]}$. The assays to determine the proliferation of spheres used bromodeoxyuridine (BrdU) Labeling and Detection Kit II (Roche, Mannheim, Germany). The enriched spheroids following treatment with BJ extract for $48 \mathrm{~h}$ were incubated in media containing $10 \mu \mathrm{M} \mathrm{BrdU}$ for 1 h. Fixatives of 3:7 mixture of $50 \mathrm{mM}$ glycine solution ( $\mathrm{pH}$ 2.0) and ethanol were added followed by incubation overnight at $-20^{\circ} \mathrm{C}$. The slides were washed with phosphate-buffered saline (PBS) and incubated at $37^{\circ} \mathrm{C}$ in a solution containing diluted anti-BrdU antibody (1:1000 dilution, GeneTex) for $30 \mathrm{~min}$. The cells were suspended in a mixture of $1 \%$ bovine serum albumin containing Alexa Fluor 488-conjugated secondary antibody (1:250 dilution) for $2 \mathrm{~h}$ in darkness. An inverted fluorescence microscope was used to record the fluorescent images. All colored images were converted to black and white by Photoshop software before being quantitated with Multi Gauge software (version 2.1, FUJIFILM). The green fluorescence intensities at each concentration as obtained were compared with that of the water control as the BrdU intensity ratio. Three independent experiments were carried out.

\section{TUNEL assay}

The apoptotic death as evaluated by terminal deoxynucleotidyl transferase-mediated dUTP nick-end labeling (TUNEL) staining of cultured spheroids and resected tissues was performed following the procedures as described previously ${ }^{[20]}$. Cells treated with BJ extract for $12 \mathrm{~h}$ underwent permeabilization and were blocked before being incubated in TUNEL reaction mixtures. The colored images were then converted to black and white by Photoshop software and quantitated with Multi Gauge software (version 2.1, 
FUJIFILM). The positively stained cells were calculated and converted into percentages. Three independent experiments were carried out.

\section{Xenograft tumor evaluation in mice}

The subcutaneous xenograft animal model was established for tumorigenesis evaluation. The three- or fourweek-old female $n u / n u$ mice were obtained from the National Applied Research Laboratories (Taipei, Taiwan). The animals were housed under aseptic and ventilated conditions free of pathogens with $12 \mathrm{~h}$ light and dark cycle. Before treatment, mice were acclimated for 7 days. The animal protocols were approved by the Animal Committee of the Institution.

A total of $8 \times 10^{4}$ of $\mathrm{H} 1975$ spheroid cells were suspended in $0.2 \mathrm{~mL}$ mixture of PBS and Matrixgel ${ }^{\mathrm{mw}}$ Basement Membrane Matrix (BD Biosciences) (1/1, v/v) and inoculated subcutaneously into the dorsal area of nude mice. Each group consisted of four mice. When the xenograft tumors reached 50-100 $\mathrm{mm}^{3}$ in size following sphere implantation for 14 days, the mice were fed orally with 2 and $4 \mathrm{~g}$ of BJ/kg in the treatment group or an equal volume of water for controls every day for 6 consecutive days. The health conditions and body weights of the animals were closely monitored. The tumor size at each time point was determined before gavage feeding. The dimensions of the xenografts (longitudinal length and transverse width) were measured using an electronic digital caliper and the measurements converted to the xenograft volume $(\pi / 6$ $\times$ width ${ }^{2} \times$ length). Sixteen days after final feeding, the mice were sacrificed under $\mathrm{CO}_{2}$ and the collected tumor samples resected for further analysis. One-way ANOVA tests were used for statistical comparisons between different groups.

Tumors were removed from the mice after being sacrificed and fixed with $5 \%(\mathrm{w} / \mathrm{v})$ freshly prepared formaldehyde overnight at room temperature. For the tissue section, the fixed tumors were sliced into 0.5-1 $\mathrm{cm}$ thick slabs and passed in the order of $10 \%, 20 \%$, and $30 \%$ (w/v, PBS) sucrose solutions. The slabs were frozen, equilibrated in a cryostat at $-20{ }^{\circ} \mathrm{C}$, and then resected by a cryostat microtome (LEICA). For immunostaining, tumor sections were incubated overnight in $5 \% \mathrm{FBS}(\mathrm{pH}$ 7.4) diluted in PBS that contained $0.2 \%$ Triton X-100. The tumor sections were washed in PBS and incubated with various primary and dye-conjugated secondary antibodies before being visualized with confocal microscopy. Tissue sections were incubated with $3 \mu \mathrm{g} / \mathrm{mL}$ of TRITC- or FITC-conjugated anti-rabbit IgG (Thermo Fisher Scientific) for $1 \mathrm{~h}$ and examined by confocal microscopy.

\section{Statistical analysis}

All data represent means \pm standard deviation of three individual experiments. The statistical analysis using Student's $t$-test was performed using GraphPad Prism 5.00 for Windows (GraphPad, San Diego, CA, USA). Statistical differences were considered significant with $P<0.05$.

\section{RESULTS}

\section{LC/MS composition analysis of aqueous BJ extract}

The obtained typical LC/MS chromatographic fingerprint profile of aqueous BJ extract showed twelve major components [Figure 1]. The resolved peaks with retention times of less than 40 min were identified as: (1) bruceoside D (PubChem CID: 10484578); (2) bruceine E (PubChem CID: 122785); (3) bruceine F (17.5 min); (4) bruceine D (PubChem CID: 441788); (5) bruceine B (PubChem CID: 161496); and (6) bruceine I (PubChem CID: 196839). The distinct peaks above 40 min included: (7) bruceine J (PubChem CID: 23656476); (8) yadanzioside F (PubChem CID: 3000798); (9) bruceantinol B (PubChem CID: 23656477); (10) brusatol (PubChem CID: 73432); (11) bruceine A (PubChem CID: 160006); and (12) bruceoside E (PubChem CID: 3000803). 
ESI(+)
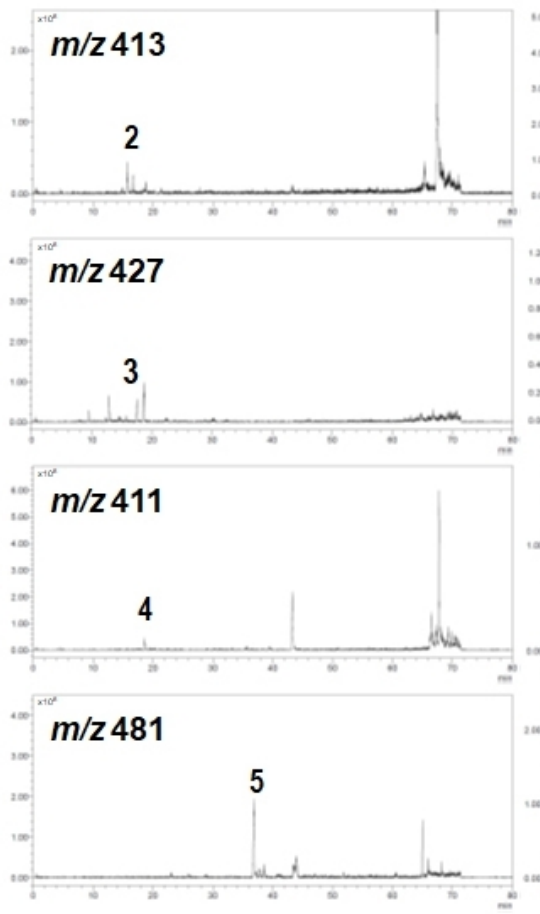

$\underline{1}$ Bruceoside D
$\underline{2}$ Bruceine E
$\underline{3}$ Bruceine F
$\underline{4}$ Bruceine D

\begin{abstract}
$10.6 \mathrm{~min}$ $15.7 \mathrm{~min}$ $17.5 \mathrm{~min}$ $18.6 \mathrm{~min}$
\end{abstract}

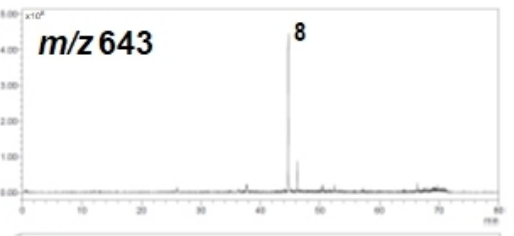

$m / z 521$

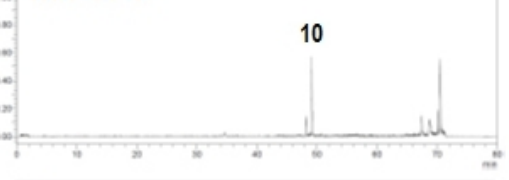

\section{$m / z 523$}

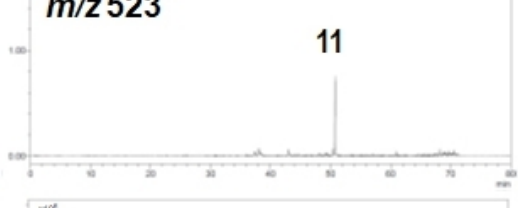

$m / z 671$

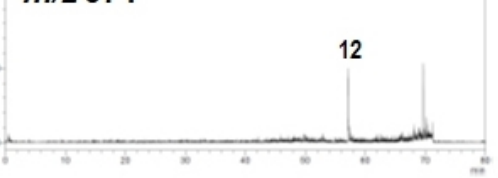

$\underline{5}$ Bruceine B

$\underline{6}$ Bruceine I

$37.0 \mathrm{~min}$

7 Bruceine $\mathrm{J}$

$39.2 \mathrm{~min}$

$44.2 \mathrm{~min}$

8 Yadanzioside F $44.7 \mathrm{~min}$
ESI(-)

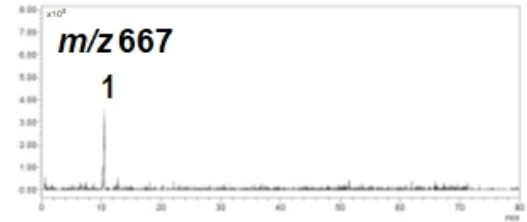

$m / z 435$
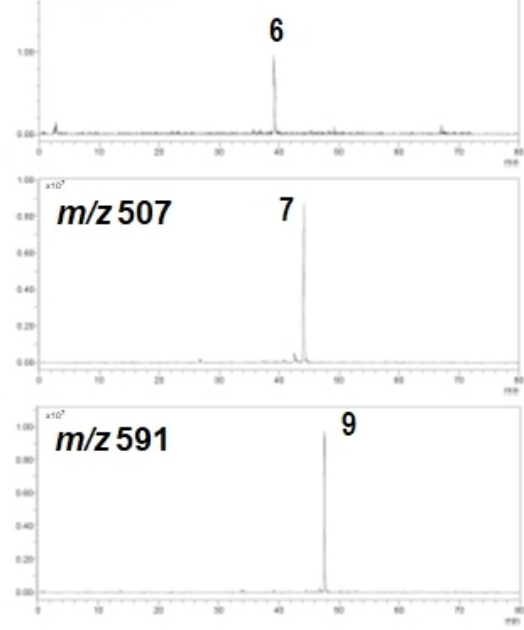

9 Bruceantinol B $47.7 \mathrm{~min}$ 10 Brusatol $\quad 49.2 \mathrm{~min}$ 11 Bruceine A $50.8 \mathrm{~min}$ 12 Bruceoside E $57.2 \mathrm{~min}$

Figure 1. LC/MS fingerprint analysis. Chromatographic fingerprint analysis was conducted using LC/MS analysis. In total, 12 bioactive marker substances from ingredients of the BJ were identified within 80 min under the selected LC/MS condition. The peaks at the specific retention time were: bruceoside $D$ (Peak 1, $10.6 \mathrm{~min}$ ), bruceine $E$ (Peak 2, $15.7 \mathrm{~min}$ ), bruceine $F$ (Peak 3, 17.5 min), bruceine $D$ (Peak 4, $18.6 \mathrm{~min}$ ), bruceine b (Peak 5, $37.0 \mathrm{~min}$ ), bruceine I (Peak 6, $39.2 \mathrm{~min}$ ), bruceine J (Peak 7, 44.2 min), yadanzioside F (Peak 8, $44.7 \mathrm{~min}$ ), bruceantinol B (Peak 9, $47.7 \mathrm{~min}$ ), brusatol (Peak 10, $49.2 \mathrm{~min}$ ), bruceine A (Peak 11, 50.8 min), bruceoside E (Peak 12, 57.2 $\min )$.

BJ extract reduced the growth of cell spheroids

A previous study revealed that the aqueous BJ extract was effective in inhibiting the proliferation of NSCLC cells $\mathrm{H} 1975^{[22]}$. To raise lung cancer tumorspheres, the adherent cells were cultured in a serum-free medium containing various growth factors. Under ultra-low attached environments, the residual cells formed suspension clusters. Growing in anchorage-independent conditions for 7 days, the distinctive bodies showing three-dimensional and well-rounded tumorsphere structures were gradually ameliorated by increasing BJ extract concentrations. In soft agar assay, the increased BJ concentrations progressively ameliorated H1975 spheroid clone numbers after 28 days [Figure 2A]. The concentration that inhibited 50\% of spheroid colony-forming capacity was determined as $10 \mathrm{mg} \mathrm{BJ} / \mathrm{mL}$ [Figure $2 \mathrm{~B}$ ].

The aqueous BJ extract diminished stem cell profiles and enhanced apoptosis characteristics of H1975 spheroids under cultured conditions

The developed spheroids suspended in serum-free medium were treated with 5,10 , and $15 \mathrm{mg} \mathrm{BJ} / \mathrm{mL}$, respectively, of BJ extract for $12 \mathrm{~h}$ and collected. Western blot analysis of the protein lysates showed that BJ reduced EGFR, decreased phosphorylated $\mathrm{EGFR}^{\mathrm{Y} 1068}$, diminished Akt expression, and impaired $\mathrm{Akt}^{\mathrm{S} 473}$ phosphorylation [Figure 2C]. The reduced Nanog and CD133 intensities of the spheroid lysates meant 
A
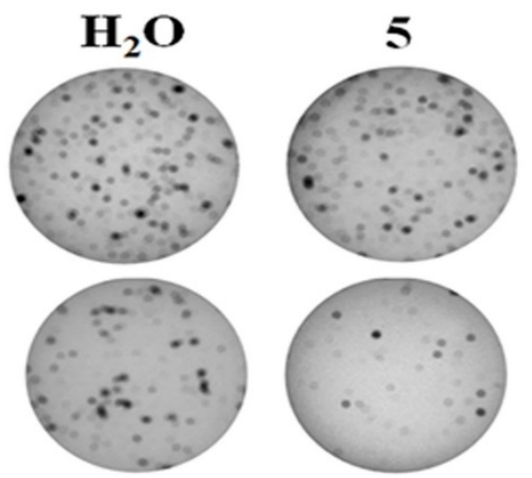

10
$15 \mathrm{mg} \mathrm{BJ} / \mathrm{ml}$

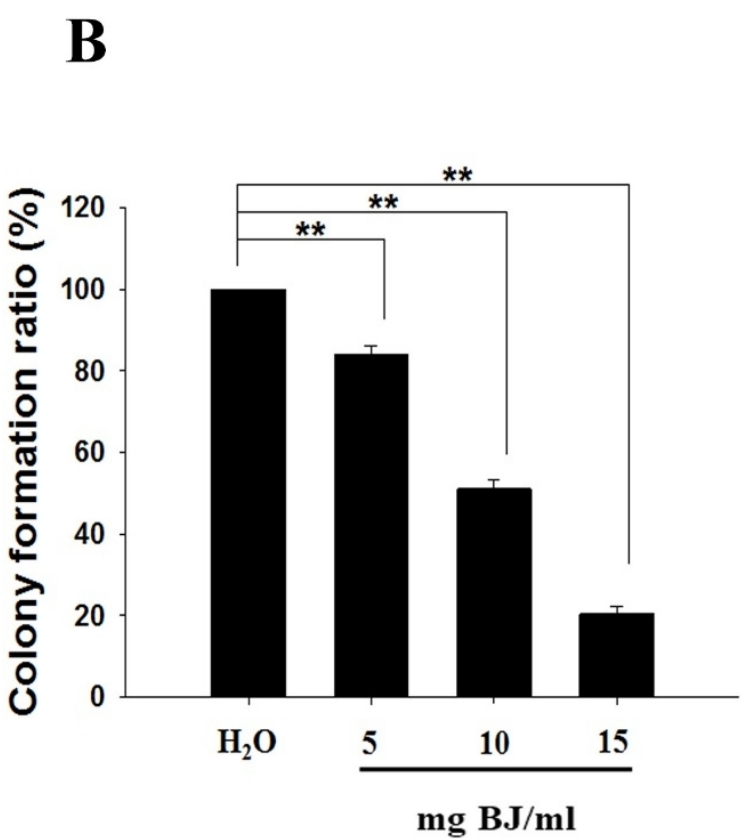

C

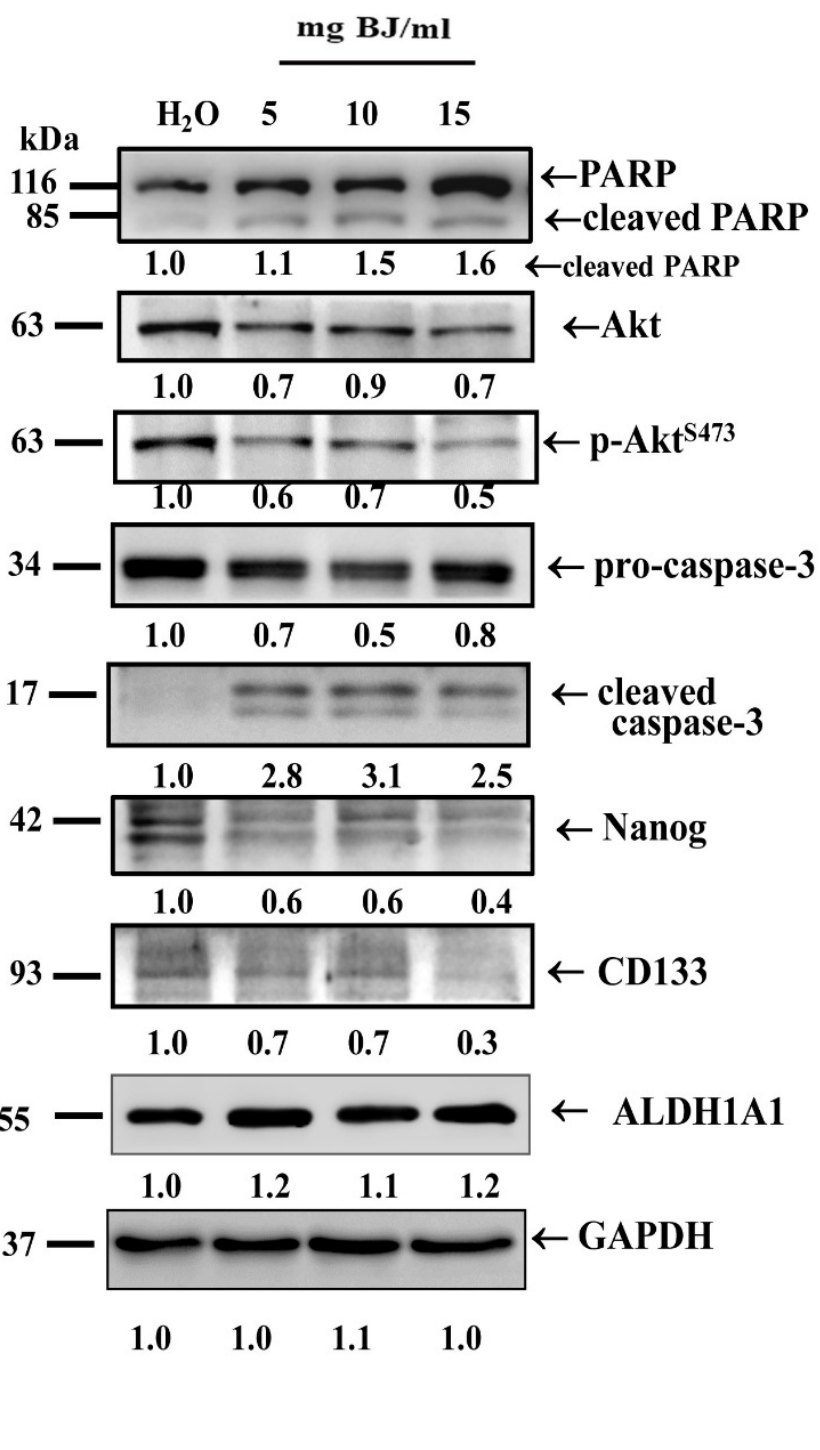

Figure 2. BJ affected the growth of multicellular H1975 spheroids. (A) Soft agar colony-forming assay. The multicellular spheroids treated with 5,10 , and $15 \mathrm{mg} / \mathrm{mL}$ of BJ extract were grown in soft agar for 28 days and the plates were stained with crystal violet, as described in "Methods". (B) Statistical analysis. The number of positive soft agar colonies of H1975 spheroids under each concentration was counted and plotted. Colonies containing more than 50 cells were counted as positive. ${ }^{\star \star} P<0.01$ indicates a significant difference between BJ treatment groups and water control from three independent experiments. (C) BJ extract reduced H1975 spheroid stemness markers. Cell lysates from H1975 spheroids as treated with BJ extract for $12 \mathrm{~h}$ were subjected to Western blot analysis. The blots were incubated with primary antibodies and analyzed for expressions of apoptosis and stemness markers with GAPDH as loading control, as described in "Methods". The numbers underneath indicate the relative intensities compared with water treatment.

stemness attenuation as BJ concentrations were increased, whereas the intensities of cell membrane stem cell marker aldehyde dehydrogenase $1 \mathrm{~A} 1(\mathrm{ALDH} 1 \mathrm{~A} 1)$ remained unchanged. Moreover, the cleavage of both poly(adenosine diphosphate ribose) polymerase (PARP) and procaspase-3 together with the appearance of active caspase 3 suggested that BJ extract induced apoptotic cell death in H1975 tumorspheres under cultured conditions.

Gavage feeding of nude mice with BJ reduced the growth of xenograft tumors with inoculated 


\section{spheroids}

Xenograft tumors in nude mice appeared 14 days after inoculating each mouse with $8 \times 10^{4}$ spheroids as enriched from H1975 cells. Mice that received 2 and $4 \mathrm{~g}$ of BJ/kg showed steady relief of tumor burden compared with those fed with water alone [Figure $3 \mathrm{~A}]$. There was no apparent bodyweight loss in nude mice orally administered with aqueous BJ extract and water control [Figure 3B]. The increased BJ concentrations reduced the weight of dissected tumors [Figure $3 \mathrm{C}$ ]. Tissues collected from tumors in mice fed with BJ displayed emerging apoptotic features in the histological images stained with hematoxylin and eosin. The apparent cytoplasm contraction, pyknosis, and interstitial space enlargement in tumor cells were increasingly visible in $\mathrm{BJ}$-fed mice that differed from water control animals, in which the tumor cells were visibly viable [Figure $3 \mathrm{D}]$.

The increased apoptosis and reduced PCNA of the implanted tumors in mice with administrated BJ The increasing TUNEL fluorescence in tissue sections from mice fed with BJ extract from 2 to $4 \mathrm{~g} / \mathrm{kg}$ indicated the onset of apoptosis [Figure 4A]. The accentuated TUNEL fluorescence intensities meant elevated apoptotic death in tumors of mice receiving increasing extract concentrations in contrast with groups fed with water alone [Figure $4 \mathrm{~B}$ ]. Furthermore, the suppressed tumor growth in groups receiving extract showed diminished fluorescent mitotic index proliferating cell nuclear antigen (PCNA) [Figure 4C]. The distinct reduction of nuclear PCNA staining in the resected specimen demonstrated that BJ-induced apoptosis alleviated growth of xenograft tumors established by the inoculated spheroids [Figure 4D].

The regressed fluorescent EGFR, $\mathrm{pEGFR}^{\mathrm{Y} 1068}$ and stemness markers in lung spheroid tumors

Administration of $\mathrm{BJ}$ diminished the intensive fluorescent EGFR [Figure 5A] and phosphorylated $\mathrm{EGFR}^{\mathrm{Y} 1068}$ [Figure 5B] in tumor dissections, as indicated by antibody detection. In addition, BJ decreased fluorescent self-renewal signals including nucleus transcription factor Nanog that regulates the pluripotent inner cell mass during embryonic development ${ }^{[23]}$. In contrast, the cell surface stem cell indicator ALDH1A1 remained intact in the dissected H1975 spheroid tumor tissues within the concentration ranges [Figure 5C]. The emergent fluorescent puncta composed of coalesced green Mitotracker and the released red cytochrome $c$ from mitochondria were clearly visible in tumor section images. The results suggest the emergent apoptotic death of $\mathrm{H} 1975$ spheroid tumor cells in mice receiving BJ extract [Figure 5D].

\section{The relapsed stem cell signatures accompanied with drug resistance marker in spheroid tumors}

The embryonic stem cell transcription factors Sox 2 and Nanog are crucial in maintaining stemness features of tumorspheres originated from lung cancer ${ }^{[24]}$. The fluorescent stem cell markers including extracellular CD133 and nucleus Nanog were eradicated in spheroid tumors [Figure 6A]. The increased BJ concentrations reduced coalesced fluorescent nuclear stem cell markers Sox2 and Nanog [Figure 6B]. Cancer resistance protein ATP-binding cassette subfamily G member 2 (ABCG2) is presented primarily in stem cell membranes of lung cancer tumors ${ }^{[2]}$. The decreased dual staining of cell surface ABCG2 and nuclear Nanog signaled abolishment of drug resistance in H1975 sphere tumors following administration of BJ [Figure 6C].

\section{The attenuated EMT and c-Met in tumors of mice receiving BJ}

NSCLC stem cells with T790M EGFR with intensive EMT are known to be insensitive to TKI treatment ${ }^{[10]}$. The acquired embryonic stem cell-like signature and the emerged EMT in tumorspheres are closely related $^{[24]}$. The induced EMT characters in the emergent stem cell-like features is a key process by which cancer cells acquire invasive and metastatic phenotypes ${ }^{[25,26]}$. In CSC-implanted tumors from mice treated with increasing BJ extract concentrations, the intrinsic EMT markers were dissipated as indicated by the attenuated $\beta$-catenin [Figure $7 \mathrm{~A}$ ] and the reduced vimentin [Figure $7 \mathrm{~B}$ ] signals. 

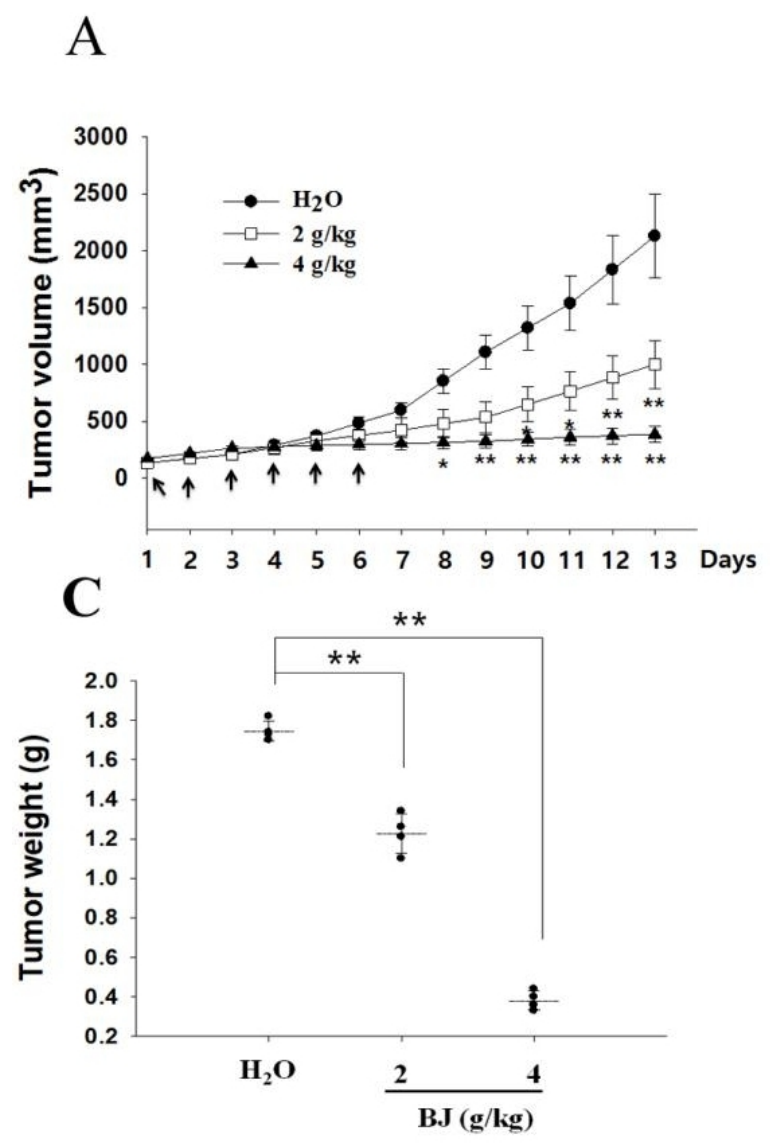
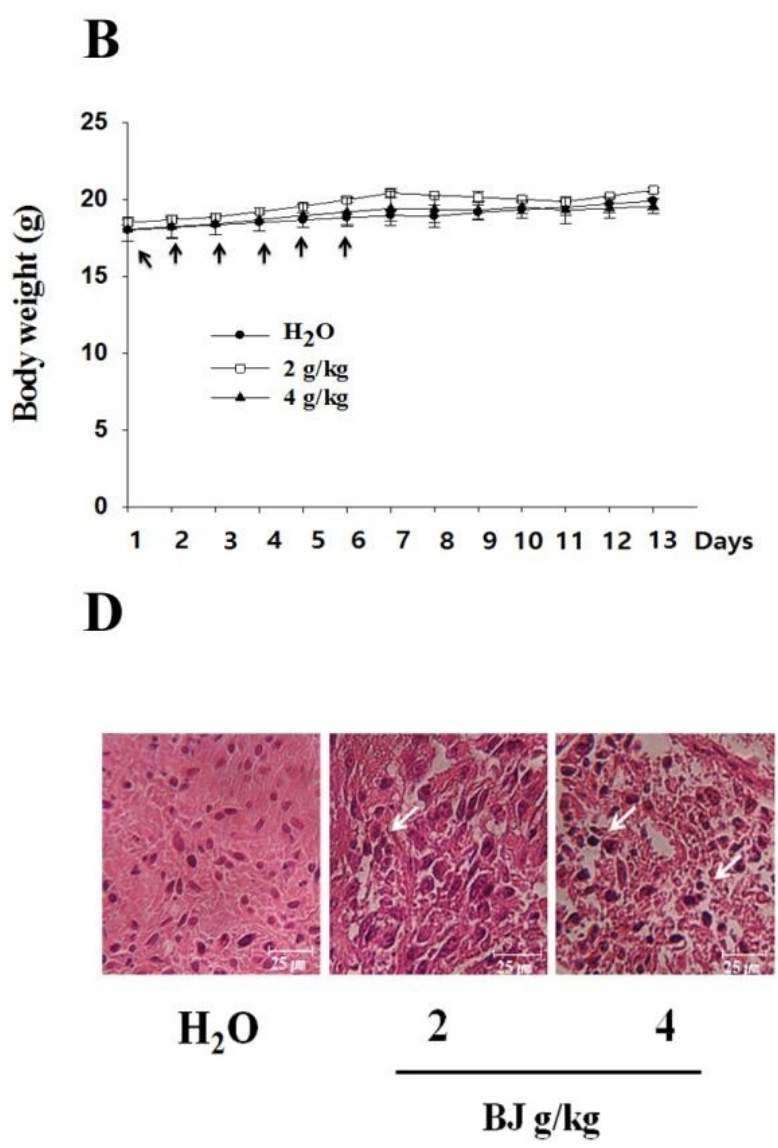

Figure 3. Oral administration of BJ reduced xenograft spheroid tumor growth. (A) BJ extract suppressed the growth of xenograft tumors. Nude mice with established xenograft spheroid tumors of $\mathrm{H} 1975$ cells as described in "Methods" were administered orally with 2 and $4 \mathrm{~g}$ of $\mathrm{BJ} / \mathrm{kg}$ daily for 6 consecutive days (arrow). Each group contained four mice. The graph represents tumor growth variation ( $y$-axis) from the start of feeding ( $x$-axis). ${ }^{\star \star} P<0.01$ indicates a significant difference in the measured tumor volumes between mice fed with 2 and $4 \mathrm{~g} \mathrm{BJ} / \mathrm{kg}$ and those with water from three individual experiments with four mice in each group. (B) The bodyweight of nude mice. No significant differences of the average body weight in mice with established xenograft tumors orally administered with water and BJ extract daily for 6 consecutive days (arrow) were found. The graph represents variations of mice weight ( $y$-axis) from the start of feeding in days (x-axis). (C) Resected tumor weight reduction. Tumor weights of the xenograft tumors were measured in mice with gavage feeding of $\mathrm{BJ}$ in comparison with those of water. The horizontal bars represent mean values of tumor mass as collected following different treatments. ${ }^{\star \star} P<0.01$ indicates significant weight difference between mice fed with 2 and $4 \mathrm{~g}$ of $\mathrm{BJ} / \mathrm{kg}$ and those with water. The graph is representative of three independent experiments. (D) Hematoxylin and eosin (HE) staining. The paraffin-embedded spheroid tumors as treated with BJ ( 2 and $4 \mathrm{~g} / \mathrm{kg}$ ) and water-fed mice control were dissected, stained with $\mathrm{HE}$, and analyzed by confocal microscopy (scale bar, $25 \mu \mathrm{m}$ ). The white arrow signifies apoptotic body location.

Activation of c-Met-hepatocyte growth factor axis constitutes a major obstacle that contributes to gefitinib resistance $^{[27]}$. EGFR T790M mutation and c-Met amplification are related to resistance to EGFR-TKI ${ }^{[28]}$. BJ was also shown effective at mitigating c-Met signaling as lung cancer spheroid tumors were gradually eliminated [Figure $7 \mathrm{C}$ ].

\section{DISCUSSION}

Human tumor cells endowed with self-renewal ability and stemness characteristics were tumorigenic and impermeable to treatment ${ }^{[3]}$. Tumorspheres from H1975 cells were developed as cluster suspension and cultured in serum-free medium supplemented with growth factors. The aqueous extract with identified bruceolide quassinoid mixture is effective against human lung cancer H1975 cells with double mutant $\mathrm{EGFR}^{[22]}$. In this study, the formation of the enriched tumorspheres was further proved susceptible to 
A

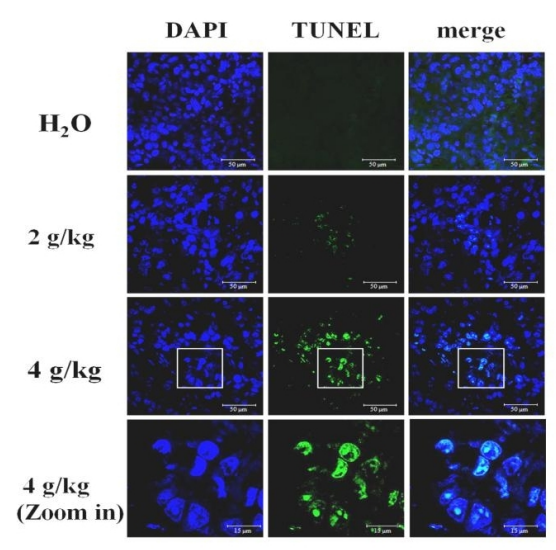

C

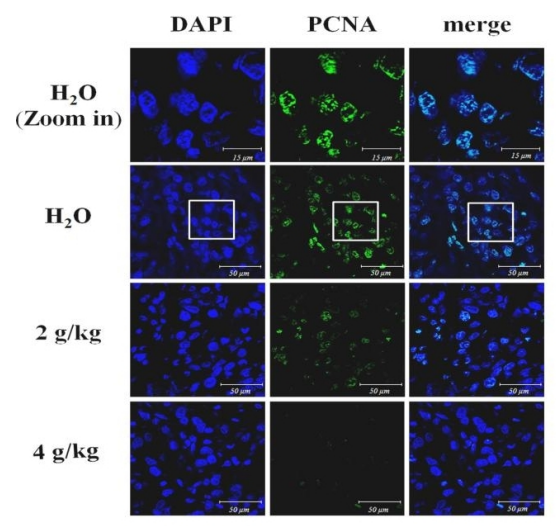

B

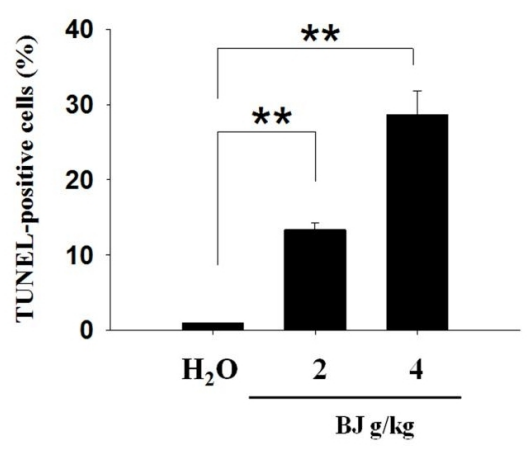

D

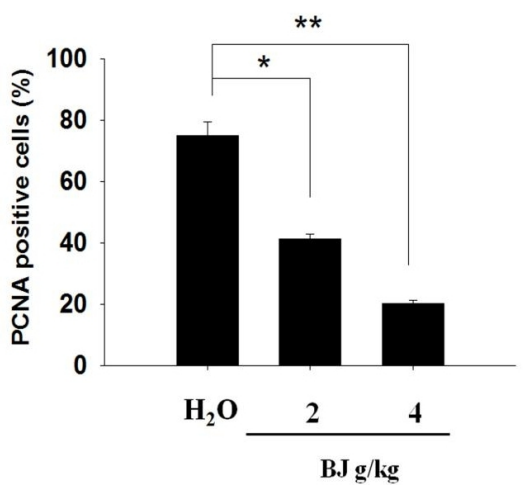

Figure 4. Spheroid tumor growth suppression. (A) Dose-dependent increase of TUNEL staining. The resected tumors in mice fed with water, 2 and $4 \mathrm{~g}$ of $\mathrm{BJ} / \mathrm{kg}$ were frozen, resected, fixed, and subjected to TUNEL experiment for confocal microscopy analysis as described in "Methods". The apoptotic bodies (green) were counter-stained with DAPI (blue) and visualized (scale bar, $50 \mu \mathrm{m}$ ). The image in the rectangular inset of tumor sections in mice treated with $4 \mathrm{~g}$ of $\mathrm{BJ} / \mathrm{kg}$ is zoomed in at the bottom of the panel (scale bar, 15 $\mu \mathrm{m})$. (B) BJ increased nucleus TUNEL-positive intensities. The numbers of fluorescent TUNEL-positive cells in each field containing 100 cells as marked by DAPI staining were counted. The numbers at various BJ concentrations were the average of at least three different fields. The data were expressed as mean averages of three individual experiments $\left({ }^{\star} P<0.01\right)$. (C) Dose-dependent decrease of stained nucleus mitotic index PCNA. The tumor sections were incubated with rabbit antibody against PCNA followed by FITCconjugated secondary antibody. The slides with PCNA fluorescence (green) were counterstained with DAPI (blue) before being analyzed confocal microscopy (scale bar, $50 \mu \mathrm{m}$ ). The images in the rectangular inset of tumor sections in mice treated with water are zoomed in at the top of the panel (scale bar, $15 \mu \mathrm{m}$ ). (D) BJ decreased nucleus PCNA signals. The number of fluorescent nucleus PCNA-positive cells in each field containing 100 cells as marked by DAPI staining was counted. The numbers of various BJ concentrations were the averages of at least three different fields. The data were expressed as mean averages of three individual experiments $\left({ }^{\star} P<0.05,{ }^{\star \star} P<0.01\right)$.

aqueous BJ extract. Inhibition of $50 \%$ of spheroid colony-forming capacity was determined at $10 \mathrm{mg} / \mathrm{mL}$ as a result of the induced apoptosis and the reduced stemness properties.

Orally administered BJ successfully eliminated H1975 spheroid tumor burden without affecting animal healthiness. Fluorescent analysis of the dissected tumor tissues showed that BJ extracts reduced fluorescent EGFR and its phosphorylated forms. The enriched stem cell signatures, including pluripotent stem cell markers CD133 and Sox2, drug resistance marker ABCG2, and transcriptional factor Nanog in H1975 spheroid tumors, were all reduced in tumors of mice administered with BJ extract. However, the surface 
A

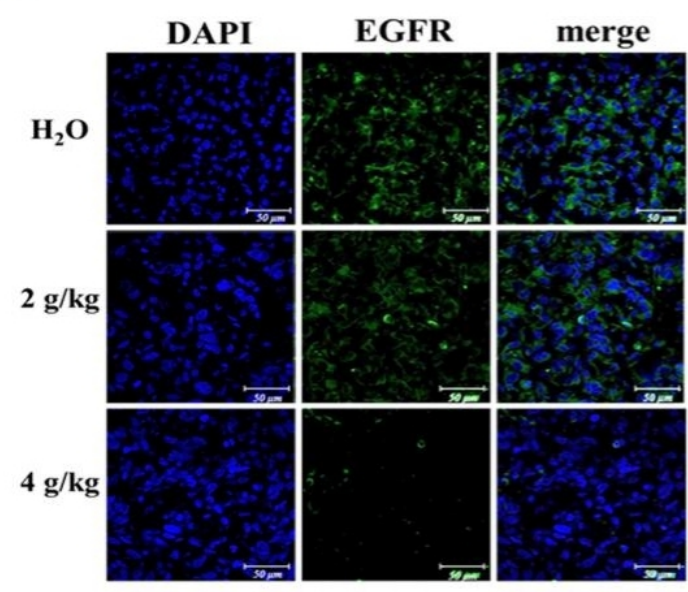

$\mathrm{C}$
$\mathrm{H}_{2} \mathrm{O}$

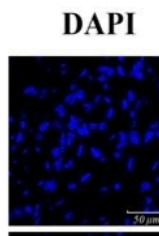

$2 \mathrm{~g} / \mathrm{kg}$
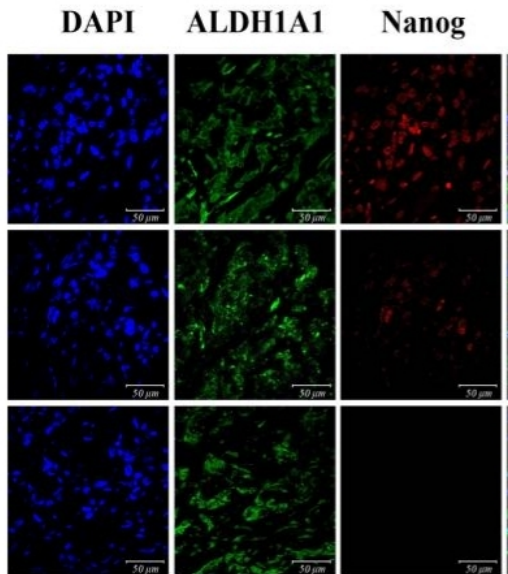
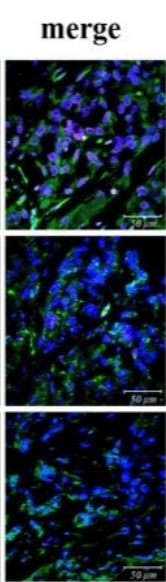

B
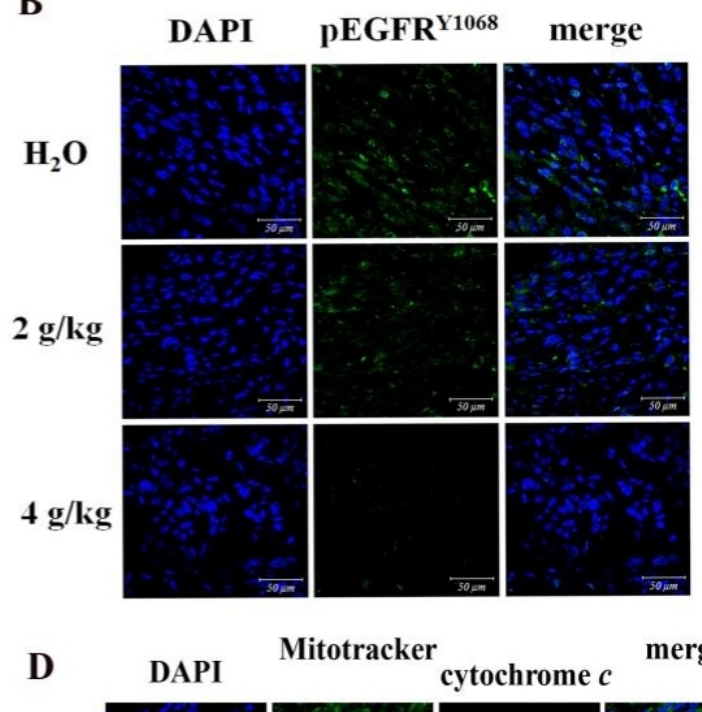

Mitotracker cytochrome $c$

merge

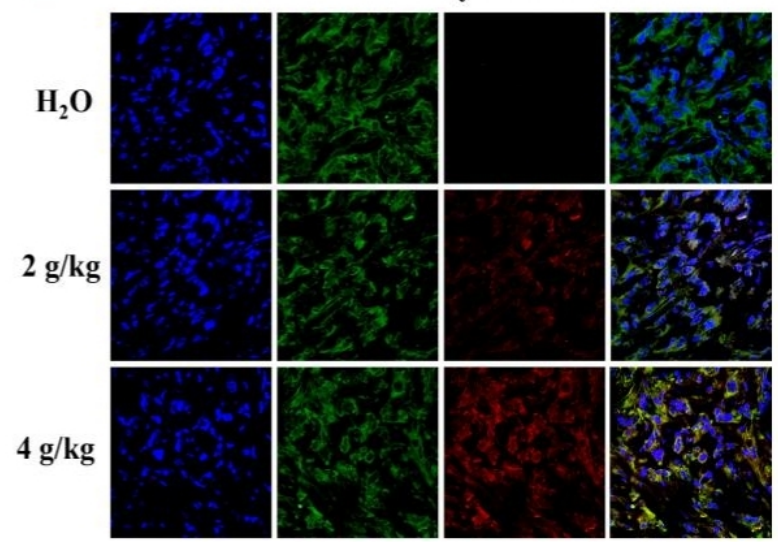

Figure 5. Fluorescence examination of the resected spheroid tumors. (A) Images of immuno-fluorescent EGFR. H1975 spheroid tumor sections from mice fed with 2 and $4 \mathrm{~g} / \mathrm{kg}$ of BJ and water control were incubated with EGFR antibody (green) followed by FITCconjugated secondary antibody treatment before being counter-stained with DAPI (blue) (scale bar, $50 \mu \mathrm{m}$ ). (B) Images of immunofluorescent pEGFR ${ }^{\text {1068 }} \mathrm{H} 1975$ spheroid tumor sections from mice fed with 2 and $4 \mathrm{~g} / \mathrm{kg}$ of BJ and water control were incubated with pEGFR ${ }^{\mathrm{Y} 1068}$ antibody (green) followed by FITC-conjugated secondary antibody treatment before being counter-stained with DAPI (blue) (scale bar, $50 \mu \mathrm{m}$ ). (C) Images of immuno-fluorescent ALDH1A1 and Nanog H1975 spheroid tumor sections from mice fed with 2 and 4 of $\mathrm{g} / \mathrm{kg}$ of $\mathrm{BJ}$ and water control were incubated with ALDH1A1 antibody (green) followed by FITC-conjugated secondary antibody. The Nanog antibody (red) incubation was followed by TRITC-conjugated secondary antibody before being counter-stained with DAPI (blue) and merged (scale bar, $50 \mu \mathrm{m}$ ). (D) Release of mitochondrial cytochrome $c$ in spheroid tumors. The dissected specimens of H1975 spheroid tumors as treated with BJ ( 2 and $4 \mathrm{~g} / \mathrm{kg}$ ) and the water control were fixed and incubated with antibody against cytochrome $c$ followed by staining with secondary antibody conjugated with TRITC (red). The slides were counter-stained with Mitotracker (green) and DAPI (blue) before being analyzed by confocal microscopy. The merged images from confocal microscopy with red cytochrome $c$ and green mitochondria signify the appearance of coalescence (yellow), while blue indicates the nucleus (scale bar, $50 \mu \mathrm{m}$ ).

marker specific for therapeutic resistance involving detoxification, ALDH1A1, remained intact in cultured spheres and in the established tumors at all experimental conditions. It is reasonably concluded that the established tumors were indeed from the enriched tumorspheres that can be progressively eliminated with increasing BJ extract concentrations. EGFR-mutant NSCLC cells equipped with ALDH1A1 activity are refractory to erlotinib but sensitive to active herbal ingredients ${ }^{[29]}$. Lung cancer cells with stem cell features are known to be insensitive to drug intervention ${ }^{[30]}$. More evidence suggests a linkage between undifferentiated stem cells and EMT expression ${ }^{[31]}$. Moreover, cancer cells with overexpressed EMT, intensive c-Met, and stem cell traits tend to be resistant to therapy ${ }^{[32]}$. The current study demonstrated that the growth of spheroid tumors with amplified drug resistance gene ABCG2 is suppressed by depleting stem- 


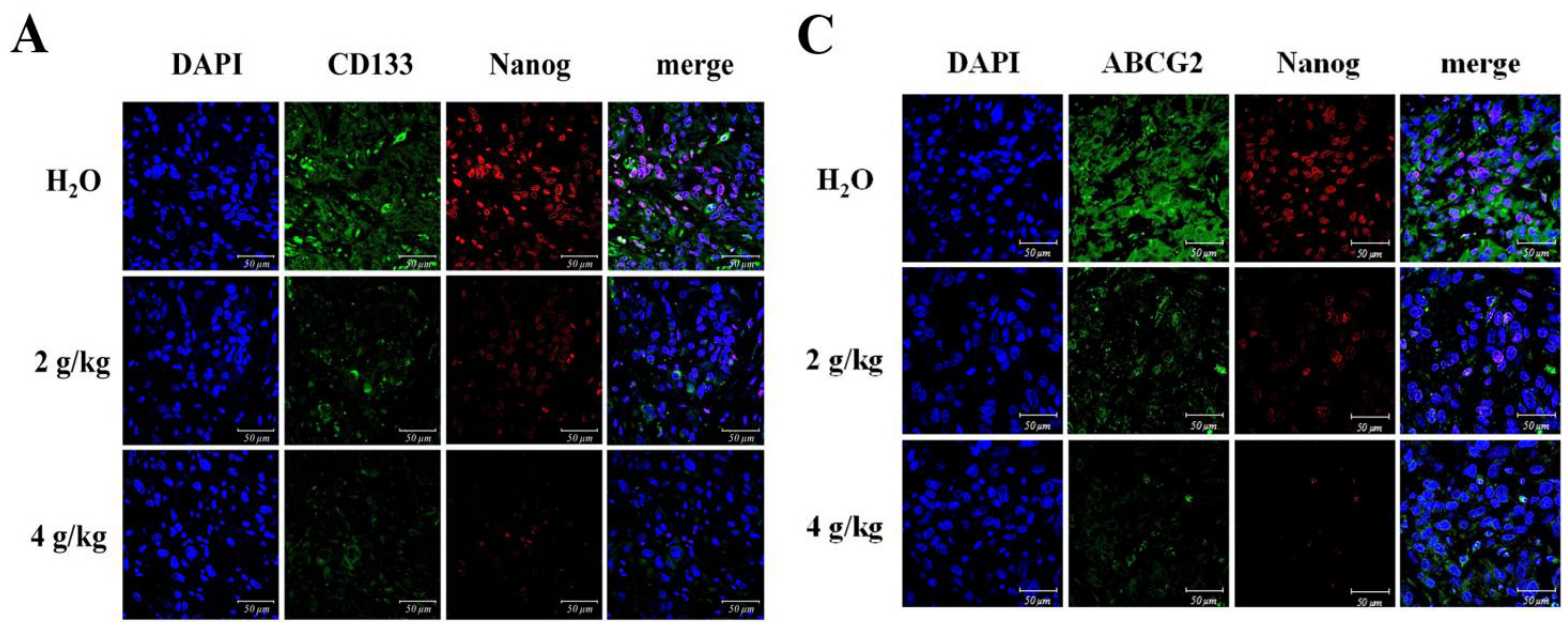

\section{B}

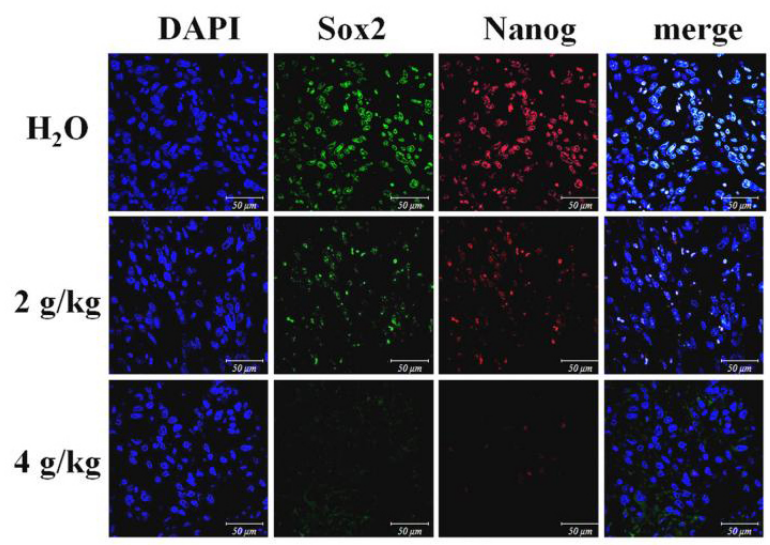

Figure 6. Fluorescent images of the resected tumor tissues: (A) the immuno-fluorescent intensities of CD133 (green) and Nanog (red); (B) the immuno-fluorescent Sox2 (green) and Nanog (red) images; and (C) the immuno-fluorescent ABCG2 (green) and Nanog (red) images. The spheroid tumor sections from mice fed with 2 and $4 \mathrm{~g} / \mathrm{kg}$ of BJ and water control were incubated with primary antibodies followed by FITC- or TRITC-conjugated secondary antibodies, before being counter-stained with DAPI (blue). Images taken from confocal microscopy were merged (scale bar, $50 \mu \mathrm{m}$ ).

like markers and promoting apoptosis in stem-like cells bearing mutant EGFR.

The common anti-cancer therapies tend to retain residual subpopulations containing mostly malignant tumor progenitor cells with poor prognosis, robust resistance to therapy, and relentless recurrence ${ }^{[3]}$. Another study suggested that a combination of herbal medicine and gefitinib helped in gefitinib efficacy in drug-resistant NSCLC by reducing c-Met and EGFR interaction ${ }^{[33]}$. The previous report showed BJ extract suppressed the growth of liver cancer stem-like cells by attenuating EGFR expression ${ }^{[20]}$. The current findings underscore the significance of the extract composed of quassinoids, which not only repressed EGFR expression but also alleviated tumor growth of lung cancer spheroids by reducing drug resistance and activating apoptosis. The decreased stem cell markers of EMT and c-Met as well as overcoming drug resistance signaled the opportunities of the BJ extract for therapy of lung cancer harboring mutated EGFR.

In conclusion, BJ extract targeted NSCLC spheroid from recalcitrant cells with double mutant EGFR. This study demonstrated the potency of aqueous BJ extract in eradicating spheroid tumors as established by NSCLC cancer tumorspheres. The study also suggested the effectiveness of oral administration of BJ extract 

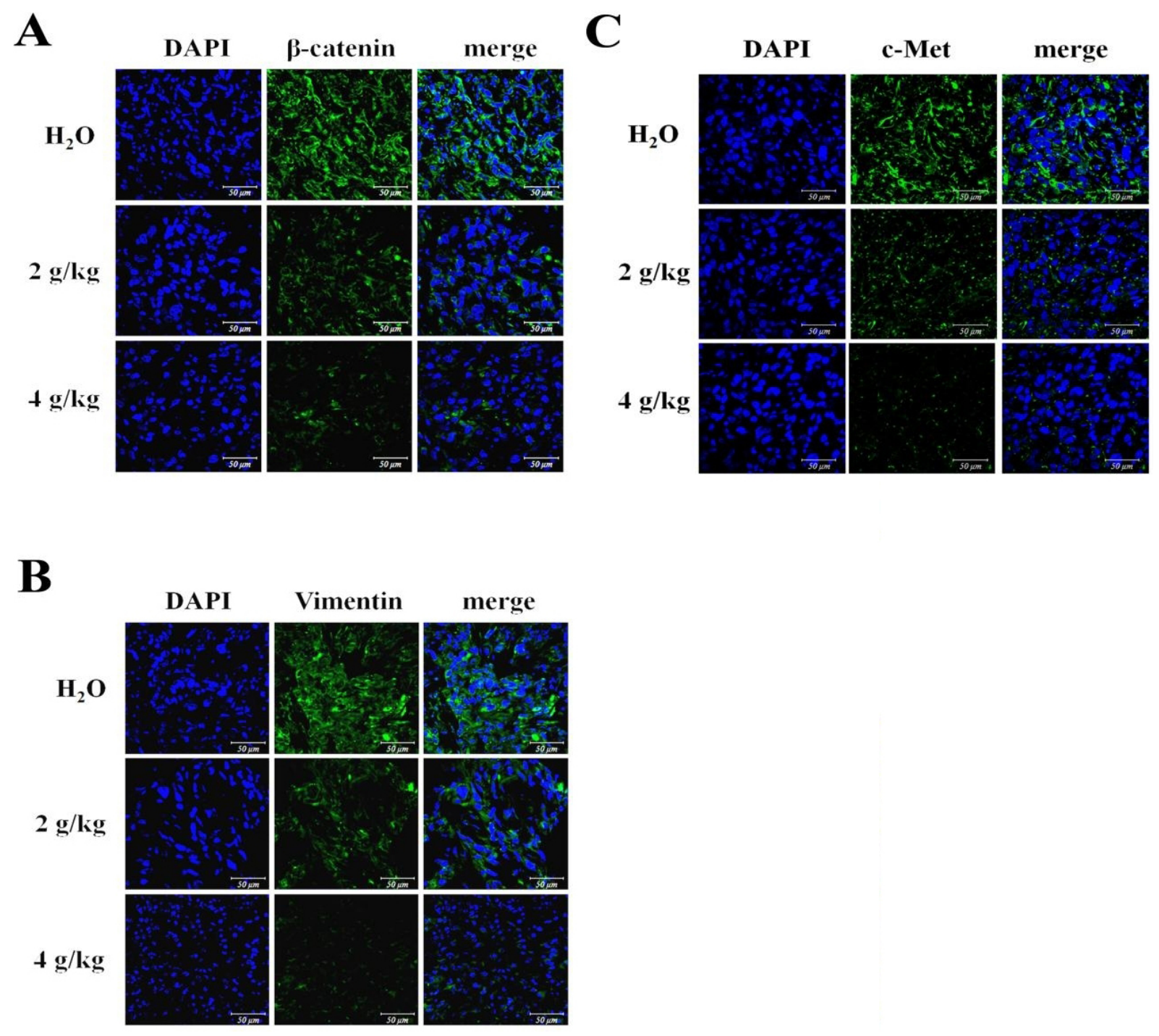

Figure 7. Fluorescent images of the resected tumor tissues: (A) the immuno-fluorescent $\beta$-catenin (green) images; (B) the immunofluorescent vimentin (green) images; and (C) the immuno-fluorescent c-Met (green) images. H1975 spheroid tumor sections from mice fed with 2 and $4 \mathrm{~g} / \mathrm{kg}$ of BJ and water control were incubated with primary antibody followed by FITC- or TRITC-conjugated secondary antibody before being counter-stained with DAPI (blue). Images from confocal microscopy were taken and merged (scale bar, $50 \mu \mathrm{m}$ ).

for clinical application. The decreased stemness property, drug resistance, and EMT of the enriched spheroids lead to the final apoptotic death of tumorspheres both in culture and in animal model. The findings also underscore that the conventional herbal medicine and its active ingredients are promising for potential translational application to eliminate lung cancer resistance to conventional therapy.

\section{DECLARATIONS}

Acknowledgments

Technical assistance of inverted and confocal laser microscopy from the School of Life Science Instrumentation Center, National Taiwan Normal University is appreciated. 


\section{Authors' contributions}

Designed experiments and developed cell culture and the related experiments and carried out animal experiments: Kim SH, Fan PW, Hsieh CH, Wang WH

Consulted and designed experiments: Lin HY

Provided and characterized the extract: Lee MC

Edited the manuscript: Lin HY, Fang K

Completed the manuscript: Fang K

Reviewed the manuscript: Kim SH, Fan PW, Hsieh CH, Lin HY, Wang WH, Lee MC, Fang K

All authors agreed to the final version of the manuscript.

\section{Availability of data and materials}

Not applicable.

\section{Financial support and sponsorship}

The work is supported by grants from Ministry of Science and Technology, Executive Yuan, ROC (MOST 104-2320-B-003-001) and National Taiwan Normal University (103T3040D2 and 104T3040C2).

\section{Conflicts of interest}

All authors declared that there are no conflicts of interest.

\section{Ethical approval and consent to participate}

Not applicable.

\section{Consent for publication}

Not applicable.

\section{Copyright}

(c) The Author(s) 2021.

\section{REFERENCES}

1. Jiang Y, Liu LS, Shen LP, et al. Traditional Chinese Medicine treatment as maintenance therapy in advanced non-small-cell lung cancer: a randomized controlled trial. Complement Ther Med 2016;24:55-62. DOI PubMed

2. Zhao W, Luo Y, Li B, Zhang T. Tumorigenic lung tumorospheres exhibit stem-like features with significantly increased expression of CD133 and ABCG2. Mol Med Rep 2016;14:2598-606. DOI PubMed PMC

3. Yakisich JS, Azad N, Venkatadri R, et al. Formation of tumorspheres with increased stemness without external mitogens in a lung cancer model. Stem Cells Int 2016;2016:5603135. DOI PubMed PMC

4. MacDonagh L, Gray SG, Breen E, et al. Lung cancer stem cells: the root of resistance. Cancer Lett 2016;372:147-56. DOI PubMed

5. Shien K, Toyooka S, Yamamoto H, et al. Acquired resistance to EGFR inhibitors is associated with a manifestation of stem cell-like properties in cancer cells. Cancer Res 2013;73:3051-61. DOI PubMed PMC

6. Leon G, MacDonagh L, Finn SP, Cuffe S, Barr MP. Cancer stem cells in drug resistant lung cancer: targeting cell surface markers and signaling pathways. Pharmacol Ther 2016;158:71-90. DOI PubMed

7. Oh SJ, Noh KH, Lee YH, et al. Targeting stemness is an effective strategy to control EML4-ALK+ non-small cell lung cancer cells. Oncotarget 2015;6:40255-67. DOI PubMed PMC

8. Signore M, Ricci-Vitiani L, De Maria R. Targeting apoptosis pathways in cancer stem cells. Cancer Lett 2013;332:374-82. DOI PubMed

9. Yang F, Yu XH, Qiao F, et al. Formulation and characterization of Brucea javanica oil microemulsion for improving safety. Drug Dev Ind Pharm 2014;40:266-77. DOI PubMed

10. Soucheray M, Capelletti M, Pulido I, et al. Intratumoral heterogeneity in EGFR-mutant NSCLC results in divergent resistance mechanisms in response to EGFR tyrosine kinase inhibition. Cancer Res 2015;75:4372-83. DOI PubMed PMC

11. Wu X, Chung VCH, Lu P, et al. Chinese herbal medicine for improving quality of life among nonsmall cell lung cancer patients: overview of systematic reviews and network meta-analysis. Medicine (Baltimore) 2016;95:e2410. DOI PubMed PMC

12. Zhao L, Li C, Zhang Y, Wen Q, Ren D. Phytochemical and biological activities of an anticancer plant medicine: Brucea Javanica. Anticancer Agents Med Chem 2014;14:440-58. DOI PubMed

13. Zhang HP, Pan JB, Zhang C, Ji N, Wang H, Ji ZL. Network understanding of herb medicine via rapid identification of ingredient- 
target interactions. Sci Rep 2014;4:3719. DOI PubMed PMC

14. Lau ST, Lin ZX, Zhao M, Leung PS. Brucea javanica fruit induces cytotoxicity and apoptosis in pancreatic adenocarcinoma cell lines. Phytother Res 2008;22:477-86. DOI PubMed

15. Yang J, Li S, Xie C, et al. Anti-inflammatory activity of ethyl acetate fraction of the seeds of Brucea Javanica. J Ethnopharmacol 2013;147:442-6. DOI PubMed

16. Liu L, Lin ZX, Leung PS, Chen LH, Zhao M, Liang J. Involvement of the mitochondrial pathway in bruceine D-induced apoptosis in Capan-2 human pancreatic adenocarcinoma cells. Int J Mol Med 2012;30:93-9. DOI PubMed

17. Xiao Z, Ching Chow S, Han Li C, et al. Role of microRNA-95 in the anticancer activity of Brucein D in hepatocellular carcinoma. Eur J Pharmacol 2014;728:141-50. DOI PubMed

18. Liu J, Huang XE, Tian GY, et al. Phase II study on safety and efficacy of Yadanzi® (Javanica oil emulsion injection) combined with chemotherapy for patients with gastric cancer. Asian Pac J Cancer Prev 2013;14:2009-12. DOI PubMed

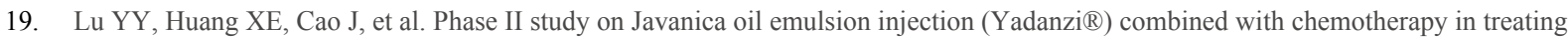
patients with advanced lung adenocarcinoma. Asian Pac J Cancer Prev 2013;14:4791-4. DOI PubMed

20. Chen JH, Kim SH, Fan PW, Liu CY, Hsieh CH, Fang K. The aqueous extract of Chinese medicinal herb Brucea javanica suppresses the growth of human liver cancer and the derived stem-like cells by apoptosis. Drug Des Devel Ther 2016;10:2003-13. DOI PubMed PMC

21. Zhang W, Lei P, Dong X, Xu C. The new concepts on overcoming drug resistance in lung cancer. Drug Des Devel Ther 2014;8:73544. DOI PubMed PMC

22. Kim SH, Liu CY, Fan PW, et al. The aqueous extract of. Brucea javanica ;10:3599-609. DOI PubMed PMC

23. Phiboonchaiyanan PP, Kiratipaiboon C, Chanvorachote P. Ciprofloxacin mediates cancer stem cell phenotypes in lung cancer cells through caveolin-1-dependent mechanism. Chem Biol Interact 2016;250:1-11. DOI PubMed

24. Bora-Singhal N, Perumal D, Nguyen J, Chellappan S. Gli1-mediated regulation of Sox2 facilitates self-renewal of stem-like cells and confers resistance to EGFR inhibitors in non-small cell lung cancer. Neoplasia 2015;17:538-51. DOI PubMed PMC

25. Chang YW, Su YJ, Hsiao M, et al. Diverse Targets of $\beta$-catenin during the epithelial-mesenchymal transition define cancer stem cells and predict disease relapse. Cancer Res 2015;75:3398-410. DOI PubMed

26. Hashida S, Yamamoto H, Shien K, et al. Acquisition of cancer stem cell-like properties in non-small cell lung cancer with acquired resistance to afatinib. Cancer Sci 2015;106:1377-84. DOI PubMed PMC

27. Ozasa H, Oguri T, Maeno K, et al. Significance of c-MET overexpression in cytotoxic anticancer drug-resistant small-cell lung cancer cells. Cancer Sci 2014;105:1032-9. DOI PubMed PMC

28. Sugano T, Seike M, Noro R, et al. Inhibition of ABCB1 overcomes cancer stem cell-like properties and acquired resistance to MET inhibitors in non-small cell lung cancer. Mol Cancer Ther 2015;14:2433-40. DOI PubMed

29. Corominas-Faja B, Oliveras-Ferraros C, Cuyàs E, et al. Stem cell-like ALDH(bright) cellular states in EGFR-mutant non-small cell lung cancer: a novel mechanism of acquired resistance to erlotinib targetable with the natural polyphenol silibinin. Cell Cycle 2013;12:3390-404. DOI PubMed PMC

30. Xu MH, Gao X, Luo D, Zhou XD, Xiong W, Liu GX. EMT and acquisition of stem cell-like properties are involved in spontaneous formation of tumorigenic hybrids between lung cancer and bone marrow-derived mesenchymal stem cells. PLoS One 2014;9:e87893. DOI PubMed PMC

31. Mani SA, Guo W, Liao MJ, et al. The epithelial-mesenchymal transition generates cells with properties of stem cells. Cell 2008;133:704-15. DOI PubMed PMC

32. Barr MP, Gray SG, Hoffmann AC, et al. Generation and characterisation of cisplatin-resistant non-small cell lung cancer cell lines displaying a stem-like signature. PLoS One 2013;8:e54193. DOI PubMed PMC

33. Han SY, Zhao W, Sun H, et al. Marsdenia tenacissima extract enhances gefitinib efficacy in non-small cell lung cancer xenografts. Phytomedicine 2015;22:560-7. DOI PubMed 